\title{
Opinion \& Special Articles: Maximizing Inclusiveness and Diversity Through Virtual Residency Applications and Interviews
}

Joshua A. Budhu, MD, Ana I. Velazquez, MD, MSc, Rana R. Said, MD, and Justin T. Jordan, MD, MPH

Neurology ${ }^{\circledR}$ 2021;97:647-650. doi:10.1212/WNL.0000000000012487
Correspondence

Dr. Budhu

jbudhu@mgh.harvard.edu

A diverse workforce is critical to providing high-quality, equitable neurologic care. Many neurologic conditions disproportionately affect Black and Latinx people, but these populations have limited access to neurologic care. ${ }^{1,2}$ Although healthcare disparities can be reduced with a diverse workforce, ${ }^{3-7}$ just $2.8 \%$ of neurologists are Black and $7.2 \%$ are Latinx, compared with the most recent US census with $12.8 \%$ of individuals identifying as Black and $18.4 \%$ as Latinx. ${ }^{8,9}$ The gap also exists at the trainee level; $4.4 \%$ of neurology residents are Black and $7.2 \%$ are Latinx. ${ }^{10}$ Recruitment of an inclusive residency class is paramount to addressing these inequities. ${ }^{3,5,7,11}$ A record of 42,508 medical students and physicians applied for residency positions in the United States in 2020-2021, as the application season moved to a virtual format because of the COVID- $19^{12}$ pandemic. Future residency application seasons will likely be a hybrid of in-person and virtual recruitment. This change presents both unique opportunities and challenges for the recruitment of a diverse and inclusive residency class. ${ }^{13}$

With careful planning, virtual recruitment and interviewing could be a powerful tool for improving equity, although virtual interviewing also carries the risk of exacerbating both conscious and unconscious bias. Residency programs, program directors, and interviewers must proactively plan to maximize inclusiveness and address bias, which otherwise could further increase gender and racial disparities in medicine. Here, we provide a number of recommendations for recruiting, interviewing, and ranking applicants in today's virtual landscape. These recommendations mainly focus on virtual recruitment, but some, such as moving to a holistic application review rather than strict United States Medical Licensing Examination (USMLE) scores or grade-point average (GPA) cutoffs, will help to improve overall diversity and inclusiveness, consistent with our field's goals. ${ }^{14,15}$

\section{Challenges}

The process of residency recruitment is fundamentally different for a virtual application season. Although these changes affect all candidates, it is important to note that in-person recruitment activities have historically been helpful toward the goal of inclusion and diversity in residency programs, ${ }^{16}$ overcoming risk of bias (in part) through relationship building. Although visiting clerkships can be a financial hardship for some, ${ }^{17}$ many programs and medical schools offer fully funded visiting clerkships for applicants who are underrepresented in medicine (UIM). Because visiting away rotations were canceled for the 2020-2021 academic year, ${ }^{18}$ UIM applicants were disproportionately affected by such closures, decreasing opportunities to obtain letters of recommendation and decreasing exposure to subspecialized fields that may be unavailable in their medical schools.

In the current era, there is an increased number of applicants-especially previously unknown applicants, which amplifies the challenge of selecting whom to interview. Many programs use USMLE and GPA cutoffs in the decision to interview applicants; however, standardized tests are notoriously biased against UIM applicants, and such cutoffs disproportionately screen out

From the Department of Neurology (J.B., J.T.J.), Massachusetts General Hospital, Harvard Medical School, Boston; Department of Medicine (A.I.V.), Division of Hematology/Oncology, University of California San Francisco; and Department of Pediatric Neurology (R.R.S.), University of Texas Southwestern Medical Center, Dallas.

Go to Neurology.org/N for full disclosures. Funding information and disclosures deemed relevant by the authors, if any, are provided at the end of the article. 
Table Key Recommendations to Maximize Inclusiveness and Diversity in Virtual Recruitment

Increase intentional outreach

- Leverage social media to highlight program's strengths, resident

experiences, and life in program's location

- Participate in virtual conferences and exhibits from minority medical

student associations

- Create virtual rotations for UIM medical students

- Host virtual open houses and networking events

Minimize bias in reviews and evaluations

- Eliminate score cutoffs and application filters

- Adopt a holistic application review and ranking process

- Provide implicit bias training to interviewers and application reviewer

- Develop structured interview guides

Create inclusive virtual interview environments

- Adopt accessible videoconferencing platforms

- Allocate time and resources for technology testing and troubleshooting

- Highlight program's commitment to diversity and ongoing efforts to

ensure an inclusive environment

- Engage diverse groups of faculty, trainees, and staff during the interview day

otherwise qualified and diverse applicants. ${ }^{11,19-21}$ With the increase in the number of applications and interviewees, the reliance on older algorithms for interviewing and ranking needs to be reevaluated.

Finally, the virtual interview format also has unique challenges that need to be addressed. ${ }^{22}$ Not every applicant has access to ideal lighting, Internet, and environment for the interview day. Virtual or video interviews inevitably lose some of the richness of human interaction, such as the loss of nonverbal cues and the addition of lag time, ${ }^{23}$ and create risk of bias. As such, finding the right program "fit" and program culture is tougher with virtual-only interviewing.

\section{Opportunities}

Although the COVID-19 pandemic has produced new challenges, it has opened many possibilities for improving diversity and inclusion. For instance, improving accessibility to educational content through virtual offerings may overcome access discrepancies for UIM students. Informational showcases that were traditionally held in person, including those of the Student National Medical Association (SNMA) and Latino Medical Student Association (LMSA), are now widely accessible in an online format (real-time and prerecordings). ${ }^{2426}$ Virtual shadowing experiences reduce financial and logistical hurdles to students gaining exposure to specialties, even if the full breadth of an away rotation is not fully recapitulated. ${ }^{27}$ Finally, creation of online educational content, such as a repository of case videos, ${ }^{28}$ may both improve house staff education and showcase the educational commitment of a program.

Virtual events and outreach to encourage relationship building and mentoring can have many more attendees now, serving as opportunities to provide more context to both programs and applicants. Although these events may provide a first glimpse of the possibility of a career in neurology for medical students at any institution, invitations should be especially directed to schools with high proportions of students who are UIM, such as historically black colleges and universities, Hispanic-serving institutions, and medical schools in Puerto Rico. ${ }^{14,15}$

One opportunity that cannot be overstated for virtual recruitment is the mitigation of financial hurdles to becoming a neurologist. Most fourth-year medical students spend between $\$ 1,000$ and $\$ 5,000$ on residency interviews, and more than $20 \%$ of students spend $>\$ 5,000 .^{17}$ Therefore, the switch to virtual interviews abrogates one of the most common financial barriers to medical student applicants. This is especially helpful for students who are UIM because they are more likely to carry student debt and less likely to have financial security and resources available for interviews. ${ }^{29,30}$ The ability to successfully match to a residency program should be based on academic merit and holistic value, not the financial ability to navigate the interview process.

\section{Recommendations}

First, programs should maintain robust outreach programs, with a focus on minority applicants. Programs should send representatives virtually to SNMA and LMSA conferences, and participate in virtual residency showcases aimed at recruiting and supporting UIM students. ${ }^{26}$ Multi-institutional educational seminars should continue, showing unity throughout our specialty. We encourage programs to use social media actively and professionally. Social media is a valuable tool for outreach toward UIM applicants, and in the absence of in-person experiences, social media helps to convey a flavor of both the location of the program and resident experiences. Groups such as the \#NeuroTwitterNetwork provide a centralized means of accessing perspective neurology trainees, whereas other groups such as \#BlackInMedicine, \#LatinxInNeuro, \#DiversityInMedicine, and @Neuro_Equity offer even more direct access to important populations. ${ }^{31}$

Next, we recommend revising interviewee selection and rank list creation, removing cutoffs for USMLE test scores or Alpha Omega Alpha membership. Instead of such heuristics, programs should develop new ways to evaluate the totality of an applicant's experience, resilience, knowledge, professionalism, enthusiasm, and willingness to work. There is evidence of reduced racial discrepancy in interview offers by eliminating a USMLE Step 1 cutoff score ${ }^{20}$ and of increased diversity in interviews and residency classes by initiating a holistic review process, focusing on applicants' diverse life experiences and commitments to the underserved. ${ }^{11,32}$ These measures ensure that qualified candidates are not "screened out" based on outdated metrics and biased admissions policies. Every application should be reviewed, and programs should move toward a mission-aligned selection process to promote equity. 
With the move to virtual interviews, many additional opportunities arise to reduce disparity and bias. We recommend that medical schools provide students with a professional virtual background. In addition, medical schools should provide virtual interview training sessions and mock interviews to decrease student anxiety and unfamiliarity with the virtual format, providing feedback on verbal and nonverbal communication. Schools should provide their applicants with suitable space on campus or access to shareable commercial space to help prevent Internet or location insecurity. It is important for interviewing residency programs to use commonly available videoconferencing platforms and provide backup telephone access to interviews in case of Internet malfunction. Programs should have staff available for troubleshooting and must ensure that interviewing faculty does not hold access issues unfavorably on scoring or recounting the interview.

Interviewers and programs should structure interviews with standardized questions to minimize variability. Unstructured interviews have been shown to incorporate bias because interviewers tend to demonstrate preferences for individuals of the same ethnic and gender background. ${ }^{33,34}$ Structured interviews with standardized questions have been shown to correlate with job performance more than unstructured interviews. ${ }^{35}$ An alternative to standardized questions would be using multiple mini-interviews, which combine traditional interviews with clinical scenarios and have been found to be a predictor of performance in medical school ${ }^{36}$ while also decreasing bias in the interview process. ${ }^{37}$ Interviewers should undergo implicit and unconscious bias training. In addition, residency programs that plan to return to in-person interviews should explore hybrid models that offer both virtual and inperson interviews as options to prospective applicants. Programs must ensure that the choice of virtual vs in-person format does not affect applicant scoring or ranking.

Finally, while bearing in mind the risk of burdening faculty with additional diversity tax ${ }^{38}$ a demonstration of faculty and resident diversity through interview panel members, social events, informational pamphlets, and a clear mission statement will be critical to promote inclusivity in the interview season. The Association of American Medical Colleges has published recommendations for virtual interviewing medical students; these can easily be applied as a baseline guide for residency programs. ${ }^{39}$

Lessons learned during the 2021 virtual residency recruitment and interview season have the opportunity to positively affect future generations. An intentional and purposeful virtual approach to recruitment, interviews, and ranking - with a major focus on inclusivity and diversity-has the potential to supplement the traditional interview process in perpetuity. We encourage residency programs and applicants to share challenges and successes during virtual and hybrid application seasons. Removing barriers and increasing diversity will benefit our patients, our profession, and our future (Table).

\section{Study Funding}

The authors report no targeted funding.

\section{Disclosure}

J. Budhu reports no disclosures. A.I. Velazquez's immediate family member is a former employee of Johnson \& Johnson Innovation and reports stock ownership in Portola Pharmaceuticals, Corbus Pharmaceuticals, and Midatech. R.R. Said reports no disclosures. J. Jordan is a consultant for Navio Theragnostics, CereXis, and Health2047. He also receives royalties from Elsevier. Go to Neurology.org/ $\mathrm{N}$ for full disclosures.

Appendix Authors

\begin{tabular}{lll}
\hline Name & Location & Contribution \\
\hline $\begin{array}{l}\text { Joshua A. } \\
\text { Budhu, MD }\end{array}$ & $\begin{array}{l}\text { Massachusetts General } \\
\text { Hospital, Dana-Farber } \\
\text { Cancer Institute, Harvard } \\
\text { Medical School, Boston, MA }\end{array}$ & $\begin{array}{l}\text { Conception, writing, critical } \\
\text { revision, and final approval of } \\
\text { the text }\end{array}$ \\
\hline $\begin{array}{l}\text { Ana I. } \\
\text { Velazquez, } \\
\text { MD, MSc }\end{array}$ & Eniversity of California, San & $\begin{array}{l}\text { Conception, writing, critical } \\
\text { revision, and final approval of } \\
\text { the text }\end{array}$ \\
\hline $\begin{array}{l}\text { Rana R. } \\
\text { Said, MD }\end{array}$ & $\begin{array}{l}\text { University of Texas } \\
\text { Southwestern Medical } \\
\text { Center, Dallas }\end{array}$ & $\begin{array}{l}\text { Critical revision and final } \\
\text { approval of all text }\end{array}$ \\
\hline $\begin{array}{l}\text { Justin } \\
\text { Jordan, } \\
\text { MD, MPH }\end{array}$ & $\begin{array}{l}\text { Massachusetts General } \\
\text { Hospital, Harvard Medical }\end{array}$ & $\begin{array}{l}\text { Conception, writing, critical } \\
\text { revision, and final approval of } \\
\text { all text and images }\end{array}$ \\
\hline & &
\end{tabular}

\section{References}

1. Saadi A, Himmelstein DU, Woolhandler S, Mejia NI. Racial disparities in neurologic health care access and utilization in the United States. Neurology. 2017;88(24):2268-2275.

2. Gardener H, Sacco RL, Rundek T, Battistella V, Cheung YK, Elkind MSV. Race and ethnic disparities in stroke incidence in the northern Manhattan study. Stroke. 2020: 1064-1069.

3. Wilbur K, Snyder C, Essary AC, Reddy S, Will KK, Saxon Mary. Developing workforce diversity in the health professions: a social justice perspective. Heal Prof Educ. 2020;6(2):222-229.

4. Jackson CS, Nadine Gracia J. Addressing health and health-care disparities: the role of a diverse workforce and the social determinants of health. Public Health Rep. 2014; 129(suppl 2):57-61.

5. Laveist TA, Pierre G. Integrating the 3Ds-social determinants, health disparities, and health-care workforce diversity. Public Health Rep. 2014;129(suppl 2):9-14.

6. The Health and Human Services Advisory Committee on Minority Health (ACMH). Reflecting America's Population: Diversifying a Competent Health Care Work Force for the 21st Century; 2011:25.

7. Mohile NA, Spector AR, Ebong IM, et al. Developing the Neurology Diversity Officer. Neurology. 2021;96(8):386-394. doi:10.1212/wnl.0000000000011460

8. US Census Data. 2021. Accessed April 14th, 2021. data.census.gov/cedsci/profile?q=United States\&g $=0100000$ US

9. AAN Insights 2019. Accessed April 14th, 2021. 2019. aan.com/siteassets/homepage/conferences-and-community/member-engagement/learn-about-aan-committees/board-planning/2019-insights-report.pdf

10. AAMC. Report on Residents: Table B5. Number of Active MD Residents, by Race/ Ethnicity (Alone or In Combination) and GME Specialty. 2020. aamc.org/data-reports/ students-residents/interactive-data/report-residents/2020/table-b5-md-residentsrace-ethnicity-and-specialty.

11. Barceló NE, Shadravan S, Wells CR, et al. Reimagining merit and representation: promoting equity and reducing bias in GME through holistic review. Acad Psychiatry. 2020;45(1):34-42.

12. NRMP. Advance Data Tables 2021 Main Residency Match. NRMP Match Database; 2021:1-18.

13. Nwora C, Allred DB, Verduzco-Gutierrez M. Mitigating bias in virtual interviews for applicants who are underrepresented in medicine. J Natl Med Assoc. 2020;113(1):74-76.

14. Stevens J, McClean J, Post M. AAN position: systemic racism and inequities in society. Neurology. 2020.Accessed April 14, 2021. https://www.aan.com/policy-and-guidelines/policy/position-statements/position-statement-on-systemic-racism-and-inequities-in-society/ 
15. American Academy of Neurology. Guiding Policy of Equity, Diversity, and Inclusion; 2019. aan. com/siteassets/home-page/footer/about-the-aan/policy-on-equity-diversity-and-inclusion.pdf

16. Mueller PS, McConahey LL, Orvidas LJ, Jenkins SM, Kasten MJ. The visiting medical student clerkship program at Mayo Clinic. Mayo Clin Proc. 2010;85(8):723-727.

17. Benson NM, Stickle TR, Raszka WV. Going "fourth" from medical school: fourth-year medical students' perspectives on the fourth year of medical school. Acad Med. 2015; 90(10):1386-1393.

18. AAMC. Medical Student. Away Rotations for Remainder of 2020-2021 and 2021-22 Academic Year; 2021. aamc.org/what-we-do/mission-areas/medical-education/awayrotations-interviews-2020-21-residency-cycle

19. Williams M, Kim EJ, Pappas K, et al. The impact of United States Medical Licensing Exam (USMLE ) step 1 cutoff scores on recruitment of underrepresented minorities in medicine: a retrospective cross-sectional study. Heal Sci Rep. 2020;3(2):1-8.

20. Spector AR, Railey KM. Reducing reliance on test scores reduces racial bias in neurology residency recruitment. J Natl Med Assoc. 2019;111(5):471-474.

21. Isaq NA, Bowers S, Chen ST. Taking a "step" toward diversity in dermatology: deemphasizing USMLE Step 1 scores in residency applications. Int J Women's Dermatol. 2020;6(3):209-210

22. Fuchs JW, Youmans QR. Mitigating bias in the era of virtual residency and fellowship interviews. J Grad Med Educ. 2020;12(6):674-677.

23. Levashina J, Hartwell CJ, Morgeson FP, Campion MA. The structured employment interview: narrative and quantitative review of the research literature. Pers Psychol. 2014;67(1):241-293.

24. SNMA. Redefining Obstacles as Opportunities to Transcend - AMEC; 2021. cdn.ymaws. com/snma.org/resource/resmgr/amec 2021/amec_2021 exhibitor\&adv_guid.pdf.

25. LMSA Conference. national.lmsa.net/programming/nc202 $\overline{1} /$ schedule/

26. Harvard Affiliated Residency Programs Virtual Showcase. 2020. dicp.hms.harvard.edu/ events/2020/residency-showcase

27. Franco I, Oladeru OT, Saraf A, et al. Improving diversity and inclusion in the postcoronavirus disease 2019 era through a radiation oncology intensive shadowing experience (RISE). Adv Radiat Oncol. 2021;6(1):100566.
28. Schaefer SM, Vadlamani L, Juthani P, et al. An online curriculum in movement disorders for neurology housestaff. Clin Park Relat Disord. 2020;3:100035.

29. Toretsky C, Mutha S, Coffman J. Reducing educational debt among underrepresented physicians and dentists. Heal Cent UC San Fr. 2019. Accessed April 17, 2021. https:// healthforce.ucsf.edu/sites/healthforce.ucsf.edu/files/publication-pdf/Reducing Educational Debt Among Underrepresented Physicians and Dentists.pdf

30. Kahn M, Sneed E. Promoting the affordability of medical education to groups underrepresented in the profession: the other side of the equation. AMA J Ethics. 2015; 17(2):172-175.

31. Zelikovich A. \#NeuroTwitterNetwork; 2020. docs.google.com/presentation/d/ 1GQju_NpKoqsUVVAmDYrmVrnhCCmCGIN6Lrc97X2upGM/edit\#slide=id

32. Aibana O, Swails JL, Flores RJ, Love LT. Bridging the gap: holistic review to increase diversity in graduate medical education. Acad Med. 2019;94(8):1137-1141.

33. Isaac $\mathrm{C}$, Lee $\mathrm{B}$, Carnes $\mathrm{M}$. Interventions that affect gender bias in hiring: a systematic review. Acad Med. 2009;84(10):1440-1446.

34. Segrest Purkiss SL, Perrewé PL, Gillespie TL, Mayes BT, Ferris GR. Implicit sources of bias in employment interview judgments and decisions. Organ Behav Hum Decis Process. 2006;101(2):152-167.

35. Schmidt FL, Zimmerman RD. A counterintuitive hypothesis about employment interview validity and some supporting evidence. J Appl Psychol. 2004;89(3): 553-561.

36. Eva KW, Reiter HI, Rosenfeld J, Norman GR. The ability of the multiple miniinterview to predict preclerkship performance in medical school. Acad Med. 2004; 79(10 suppl):40-42.

37. Bright CM, Price MA, Morgan RC, Bailey RK. The report of the W. Montague cobb/ NMA health institute consensus panel on the plight of underrepresented minorities in medical education. J Natl Med Assoc. 2018;110(6):614-623.

38. Rodríguez JE, Campbell KM, Pololi LH. Addressing disparities in academic medicine: what of the minority tax? BMC Med Educ. 2015;15(1):1-5.

39. Interviews Virtual. Tips for Admissions Officers. AAMC; 2020. aamc.org/media/ 44851/download

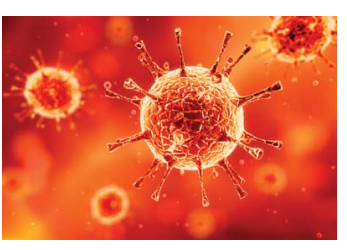

\section{COVID-19 and Neurologic Disease: Call for Papers!}

The editors of Neurology are interested in papers that address the neurological aspects of COVID-19 infection and challenges to the management of patients with chronic neurological conditions who have, or are at risk for, the infection. Relevant papers that pass initial internal review will undergo expedited peer review and online publication. We will consider papers posted in preprint servers.

Submit observational studies and clinical trials as Articles and case series and case reports under the Clinical/Scientific Notes category to https://submit.neurology.org/ today!

\section{Practice Current: An interactive exchange on controversial topics}

Share your own best practices.

Read commentary with expert opinion.

Explore results on an interactive world map.

NPub.org/NCP/practicecurrent

Neurology ${ }^{\circledR}$ Clinical Practice 


\section{Neurology}

\section{Opinion \& Special Articles: Maximizing Inclusiveness and Diversity Through Virtual Residency Applications and Interviews}

Joshua A. Budhu, Ana I. Velazquez, Rana R. Said, et al.

Neurology 2021;97;647-650 Published Online before print July 15, 2021

DOI 10.1212/WNL.0000000000012487

This information is current as of July 15, 2021

\section{Updated Information \&} Services

References

Subspecialty Collections

Permissions \& Licensing

Reprints including high resolution figures, can be found at: http://n.neurology.org/content/97/13/647.full

This article cites 24 articles, 2 of which you can access for free at: http://n.neurology.org/content/97/13/647.full\#ref-list-1

This article, along with others on similar topics, appears in the following collection(s):

Advocacy

http://n.neurology.org/cgi/collection/advocacy

All Education

http://n.neurology.org/cgi/collection/all_education

Bias, prejudice, discrimination

http://n.neurology.org/cgi/collection/bias_prejudice_discrimination

Inclusion, Diversity, Equity, Anti-racism, and Social Justice (IDEAS)

http://n.neurology.org/cgi/collection/all_equity_diversity_and_inclusio $\mathrm{n}$

Workforce diversity

http://n.neurology.org/cgi/collection/workforce_diversity

Information about reproducing this article in parts (figures,tables) or in its entirety can be found online at:

http://www.neurology.org/about/about_the_journal\#permissions

Information about ordering reprints can be found online:

http://n.neurology.org/subscribers/advertise

Neurology ${ }^{\circledR}$ is the official journal of the American Academy of Neurology. Published continuously since 1951, it is now a weekly with 48 issues per year. Copyright () 2021 American Academy of Neurology. All rights reserved. Print ISSN: 0028-3878. Online ISSN: 1526-632X.

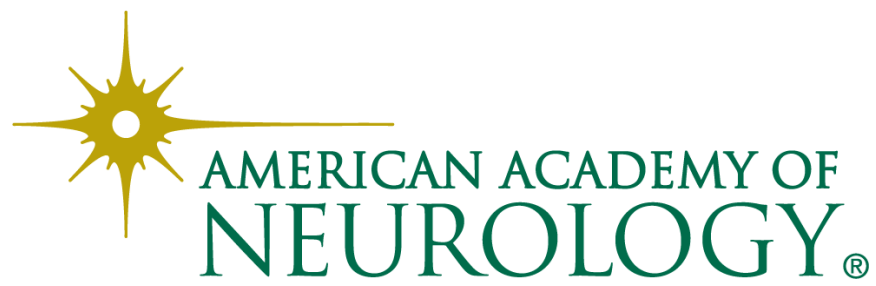

